\title{
Motivations of Play in Online Games
}

\author{
Nick Yee, Department of Communication, Stanford University \\ (in press in CyberPsychology and Behavior)
}

\begin{abstract}
An empirical model of player motivations in online games provides the foundation to understanding and assessing how players differ from one another and how motivations of play relate to age, gender, usage patterns and in-game behaviors. In the current study, a factor analytic approach was used to create an empirical model of player motivations. The analysis revealed 10 motivation subcomponents that grouped into 3 overarching components (Achievement, Social, and Immersion). Relationships between motivations and demographic variables (age, gender, and usage patterns) are also presented.
\end{abstract}

\section{Introduction}

Every day, millions of people [1] interact with each other in online environments known as Massively-Multiplayer Online Role-Playing Games (MMORPGs). MMORPG players, who on average are 26 years old, typically spend 22 hours a week in these environments [2]. Asking MMORPG players why they play reveals a wide variation of motives:

“Currently, I am trying to establish a working corporation within the economic boundaries of the virtual world. Primarily, to learn more about how real world social theories play out in a virtual economy.” [Male, 30]

"The fact that I was able to immerse myself in the game and relate to other 
people or just listen in to the 'chatter' was appealing.” [Female, 34]

Indeed, this variation suggests that MMORPGs may be appealing to so many players because they are able to cater to many different kinds of play styles. Being able to articulate and quantify these motivations provides the foundation to explore whether different sections of the player demographic are motivated differently, and whether certain motivations are more highly correlated with usage patterns or other in-game behaviors. Such a model has value for both researchers and game designers. For researchers, findings may clarify whether certain kinds of players are more susceptible to problematic usage for example. And for game developers, findings may clarify how certain game mechanics may attract or deter certain player demographics.

While Bartle’s Player Types [3] is a well-known player taxonomy of Multi-User Dungeon (MUD) users, the underlying assumptions of the model have never been empirically tested. For example, Bartle assumed that preference for one type of play suppressed (e.g., Achievement) other types of play (e.g., Socializing or Exploring). Also, it has never been empirically shown that the four Player Types are indeed independent Types. In other words, several of the Types may correlate to a high degree. In essence, it would be hard to use Bartle’s model on a practical basis unless it was validated with and grounded in empirical data. In the following work, I describe a factor analytic approach to creating an empiricallygrounded player motivation model.

\section{Method}

A list of 40 questions that related to player motivations was generated based on Bartle’s Types and qualitative information from earlier surveys of MMORPG players. Players used a 5-point fully-labeled construct-specific scale to respond. For example, respondents 
were asked, “How important is it you to level up as fast as possible?”. After the inventory of items was prepared, data was then collected from 3000 MMORPG players through online surveys publicized at online portals that catered to MMORPG players from several popular MMORPGs - EverQuest, Dark Age of Camelot, Ultima Online, and Star Wars Galaxies. A factor analysis was then performed on this data to detect the relationships among the inventory items in order to reveal its underlying structure.

\section{Results}

A principle components analysis was used to arrive at a more parsimonious representation of the 40-item inventory set. 10 components emerged with eigenvalues greater

\begin{tabular}{|c|c|c|}
\hline Achievement & Social & Immersion \\
\hline Advancement & Socializing & Discovery \\
Progress, Power, & Casual Chat, Helping Others, & Exploration, Lore, \\
Accumulation, Status & Making Friends & Finding Hidden Things \\
\hline Mechanics & Relationship & Role-Playing \\
\hline Numbers, Optimization, & Personal, Self-Disclosure, & Story Line, Character History, \\
Templating, Analysis & Find and Give Support & Roles, Fantasy \\
\hline Competition & Teamwork & Customization \\
Challenging Others, & Collaboration, Groups, & Appearances, Accessories, \\
Provocation, Domination & Group Achievements & Style, Color Schemes \\
\hline & & Escapism \\
\hline & & Relax, Escape from RL, \\
& & Avoid RL Problems \\
\hline
\end{tabular}

Figure 1: The subcomponents revealed by the factor analysis grouped by the main component they fall under.

than 1 . Together, these 10 components accounted for $60 \%$ of the overall variance. An oblique rotation (Promax, kappa=4) was used to reflect the inherent correlations between the components. Most loadings were in excess of 0.55 and no secondary loadings exceeded 30\% of the primary loadings. Almost all components had a Cronbach's alpha of over .70. Due to the high number of components, an additional PCA was performed on the 10 components in 
order to explore whether certain components should be grouped together. 3 main components emerged with eigenvalues greater than 1 . Together, these 3 main components accounted for $55 \%$ of the overall variance. Again, an oblique rotation was used. The 10 components are shown here grouped according to the second PCA (see Figure 1). The components will now be described briefly.

\section{The Achievement Component}

Advancement. The desire to gain power, progress rapidly, and accumulate in-game symbols of wealth or status.

Mechanics. Having an interest in analyzing the underlying rules and system in order to optimize character performance.

Competition. The desire to challenge and compete with others.

\section{The Social Component}

Socializing. Having an interest in helping and chatting with other players.

Relationship. The desire to form long-term meaningful relationships with others.

Teamwork. Deriving satisfaction from being part of a group effort.

\section{The Immersion Component}

Discovery. Finding and knowing things that most other players don’t know about.

Role-Playing. Creating a persona with a background story and interacting with other players to create an improvised story.

Customization. Having an interest in customizing the appearance of their character.

Escapism. Using the online environment to avoid thinking about real life problems.

The factor analysis revealed that play motivations in MMORPGs do not suppress each other as Bartle suggested. Just because a player scores high on the Achievement component 
doesn't mean they can't also score high on the Social component. This is supported by the data - correlations among the 3 main components are weak $\left(\mathrm{r}^{\prime} \mathrm{s}<.10\right)$.

Gender, age, and usage differences

Component scores were calculated for every participant using a regression method based on the factor loadings. Male players scored significantly higher on all the Achievement components than female players (t’s[3035] > 9.5, p's <.001), while female players scored significantly higher than male players on the Relationship subcomponent $(\mathrm{t}[3035]=-14.31$, $\mathrm{p}$ $<$.001]). While these results seem to confirm stereotypical assumptions of gendered play styles, the variation in the Achievement component is in fact better explained by age than gender. In a multiple regression using the Achievement motivation as a dependent variable, and gender and age as the independent variables, the resulting model had an r-squared of .15. The standardized coefficient of gender was .16; the standardized coefficient of age was -.32. Also worth noting is that there is a gender difference in the relationship subcomponent but not in the socializing subcomponent although these two subcomponents are highly related. In other words, male players socialize just as much as female players but are looking for very different things in those relationships.

To explore whether some of these motivation components might be highly correlated with, and thus perhaps predictive of, problematic usage, a variation of Kimberly Young’s [4] diagnostic questionnaire of internet users was also implemented. The resulting scale had a Cronbach's alpha of .77 and a composite value was created to indicate overall problematic usage for each respondent. A multiple regression with the problematic usage score as the dependent variable, and the ten motivation components, age, gender, and hours played per week as the independent variables revealed a significant model ( $r$-squared $=.34, p<.001$ ). 
The Escapism component emerged as the best predictor $(b=.31, p<.001)$, followed by hours played per week $(b=.30, p<.001)$, and the Advancement component $(b=.17, p<.01)$. All other predictors had a standardized coefficient of less than .10. This pattern of predictor strength dovetails with commentary from clinicians that pre-existing depression or mood disorders are common among users who develop problematic usage with online games [for example, see interview responses in 5, 6].

\section{Discussion}

Oftentimes, both the media and media effects researchers collapse all video gamers into a simplistic archetype. While this facilitates making sweeping generalizations of potentially deviant behaviors or consequences (i.e., addiction and aggression), this strategy inevitably ignores the important fact that different people choose to play games for very different reasons, and thus, the same video game may have very different meanings or consequences for different players. The study described in this paper was an attempt to articulate the myriad of motivations of play among MMO players, and an exploration of how these motivational factors can provide us with analytical tools to describe and understand the preference for and effects of game-play for different kinds of players. The empirical model developed in this study provides a solid foundation for future quantitative research in online games by providing a model to understand player motivations, a tool to assess those motivations, and thus also a means to understand usage patterns, in-game behaviors and demographic variables in relation to player motivations. 


\section{References}

1. Woodcock, B., MMOG Chart. 2005. Available at http://www.mmogchart.com/

2. Yee, N., The Demographics, Motivations, and Derived Experiences of Users of Massively Multi-User Online Graphical Environments. Presence: Teleoperators and Virtual Environments, 2006. 15: p. 309-329.

3. Bartle, R., Hearts, Clubs, Diamonds, Spades: Players Who Suit MUDs. The Journal of Virtual Environments, 1996. 1.

4. Young, K., Internet addiction: The emergence of a new clinical disorder.

CyberPsychology and Behavior, 1998. 1: p. 237-244.

5. Bean, A., The internet's dangerous power, in Washington Square News. 2006.

6. Kershaw, S., Hooked on the Web: Help is on the way, in New York Times. 2005. 
Appendix 1: Gender differences in motivation components and correlations with age and usage. ( $\mathrm{N}$ male = 2769, $\mathrm{N}$ female $=431$ )

\begin{tabular}{rcccc}
\hline & Gender Differences* & $\boldsymbol{r}^{* *}$ & $\begin{array}{c}\text { Age Correlation } \\
\text { Coefficients } \\
\mathbf{( M ~ / ~ F ) ~}\end{array}$ & $\begin{array}{c}\text { Hours Correlation } \\
\text { Coefficients } \\
\mathbf{( M ~ / ~ F ) ~}\end{array}$ \\
\hline ACHIEVEMENT & Male > Female & .26 & $-.35 /-.26$ & $.22 / .12$ \\
Advancement & Male > Female & .19 & $-.30 /-.24$ & $.20 / .10$ \\
Mechanics & Male > Female & .24 & $-.15 /-.08$ & $.17 / .12$ \\
Competition & Male > Female & .17 & $-.34 /-.27$ & $.06 /-.02$ \\
SOCIAL & Female > Male & .12 & $-.16 /-.02$ & $.05 / .11$ \\
Socializing & Female > Male & -.07 & $-.08 /-.04$ & $.05 / .07$ \\
Relationship & Female > Male & -.25 & $-.08 /-.01$ & $.11 / .15$ \\
Teamwork & --- & --- & $-.14 /-.02$ & $.01 / .05$ \\
IMMERSION & Female > Male & .15 & $-.02 /-.13$ & $.09 / .05$ \\
Discovery & --- & --- & $-.02 /-.16$ & $.05 /-.01$ \\
Role-Play & Female > Male & -.06 & $.02 /-.02$ & $-.02 / .00$ \\
Customization & Female > Male & -.18 & $-.13 /-.12$ & $.04 / .03$ \\
Escapism & Female $>$ Male & -.04 & $.02 /-.08$ & $.11 / .11$ \\
\hline
\end{tabular}

* All reported gender differences are significant at the $\mathrm{p}<.001$ level with t-tests.

** $r$ is a measure of the effect size of the gender differences (t-tests), and thus an approximation of how much the overall variance in the subcomponent can be explained by gender alone. 
Appendix 2. Inventory items listed by component, along with corresponding factor loadings. Reliability alphas of components are also shown.

\begin{tabular}{|c|c|c|}
\hline Subcomponent & Inventory Item & $\begin{array}{l}\text { Factor } \\
\text { Loading }\end{array}$ \\
\hline Advancement & Leveling up your character as fast as possible. & .68 \\
\hline \multirow[t]{5}{*}{$\alpha=.79$} & Acquiring rare items that most players will never have. & .77 \\
\hline & Becoming powerful. & .81 \\
\hline & Accumulating resources, items or money. & .69 \\
\hline & How important is it to you to be well-known in the game? & .53 \\
\hline & Being part of a serious, raid/loot-oriented guild. & .60 \\
\hline \multirow[t]{4}{*}{$\begin{array}{r}\text { Mechanics } \\
\alpha=.68\end{array}$} & $\begin{array}{l}\text { How interested are you in the precise numbers and percentages underlying the game } \\
\text { mechanics? }\end{array}$ & .78 \\
\hline & $\begin{array}{l}\text { How important is it to you that your character is as optimized as possible for their } \\
\text { profession / role? }\end{array}$ & .65 \\
\hline & $\begin{array}{l}\text { How often do you use a character builder or a template to plan out your character's } \\
\text { advancement at an early level? }\end{array}$ & .67 \\
\hline & Knowing as much about the game mechanics and rules as possible. & .69 \\
\hline Competition & Competing with other players. & .64 \\
\hline \multirow[t]{3}{*}{$\alpha=.75$} & How often do you purposefully try to provoke or irritate other players? & .81 \\
\hline & Dominating/killing other players. & .72 \\
\hline & Doing things that annoy other players. & .82 \\
\hline Socializing & Getting to know other players. & .82 \\
\hline \multirow[t]{3}{*}{$\alpha=.74$} & Helping other players. & .65 \\
\hline & Chatting with other players. & .77 \\
\hline & Being part of a friendly, casual guild. & .63 \\
\hline \multirow[t]{3}{*}{$\begin{array}{r}\text { Relationship } \\
\alpha=.80\end{array}$} & $\begin{array}{l}\text { How often do you find yourself having meaningful conversations with other } \\
\text { players? }\end{array}$ & .71 \\
\hline & How often do you talk to your online friends about your personal issues? & .88 \\
\hline & $\begin{array}{l}\text { How often have your online friends offered you support when you had a real life } \\
\text { problem? }\end{array}$ & .86 \\
\hline Teamwork & Would you rather be grouped or soloing? & .79 \\
\hline \multirow[t]{3}{*}{$\alpha=.71$} & How important is it to you that your character can solo well? & .77 \\
\hline & How much do you enjoy working with others in a group? & .60 \\
\hline & Having a self-sufficient character. & .63 \\
\hline Discovery & How much do you enjoy exploring the world just for the sake of exploring it? & .82 \\
\hline \multirow[t]{3}{*}{$\alpha=.73$} & $\begin{array}{l}\text { How much do you enjoy finding quests, NPCs or locations that most people do not } \\
\text { know about? }\end{array}$ & .77 \\
\hline & $\begin{array}{l}\text { How much do you enjoy collecting distinctive objects or clothing that have no } \\
\text { functional value in the game? }\end{array}$ & .55 \\
\hline & Exploring every map or zone in the world. & .80 \\
\hline Role-Playing & Trying out new roles and personalities with your characters. & .66 \\
\hline$\alpha=.87$ & Being immersed in a fantasy world. & .62 \\
\hline
\end{tabular}


How often do you make up stories and histories for your characters?

How often do you role-play your character? $\quad .85$

Customization $\quad$ How much time do you spend customizing your character during character $\quad .73$

$\alpha=.74$ creation?

How important is it to you that your character's armor / outfit matches in color and $\quad .81$

style?

How important is it to you that your character looks different from other characters? $\quad .80$

Escapism How often do you play so you can avoid thinking about some of your real-life $\quad .81$

$\alpha=.65$ problems or worries?

How often do you play to relax from the day's work? $\quad .62$

Escaping from the real world. $\quad .83$ 